\title{
Noble gas constraints on air-sea gas exchange and bubble fluxes
}

\author{
Rachel H. R. Stanley, ${ }^{1}$ William J. Jenkins, ${ }^{1}$ Dempsey E. Lott III, ${ }^{1}$ and Scott C. Doney ${ }^{1}$ \\ Received 20 March 2009; revised 19 July 2009; accepted 17 August 2009; published 19 November 2009.
}

[1] Air-sea gas exchange is an important part of the biogeochemical cycles of many climatically and biologically relevant gases including $\mathrm{CO}_{2}, \mathrm{O}_{2}$, dimethyl sulfide and $\mathrm{CH}_{4}$. Here we use a three year observational time series of five noble gases ( $\mathrm{He}, \mathrm{Ne}, \mathrm{Ar}, \mathrm{Kr}$, and $\mathrm{Xe}$ ) at the Bermuda Atlantic Time series Study (BATS) site in tandem with a onedimensional upper ocean model to develop an improved parameterization for air-sea gas exchange that explicitly includes separate components for diffusive gas exchange and bubble processes. Based on seasonal timescale noble gas data, this parameterization, which has a $1 \sigma$ uncertainty of $\pm 14 \%$ for diffusive gas exchange and $\pm 29 \%$ for bubble fluxes, is more tightly constrained than previous parameterizations. Although the magnitude of diffusive gas exchange is within errors of that of Wanninkhof (1992), a commonly used parameterization, we find that bubble-mediated exchange, which is not explicitly included by Wanninkhof (1992) or many other formulations, is significant even for soluble gases. If one uses observed saturation anomalies of $\mathrm{Ar}$ (a gas with similar characteristics to $\mathrm{O}_{2}$ ) and a parameterization of gas exchange to calculate gas exchange fluxes, then the calculated fluxes differ by $\sim 240 \%$ if the parameterization presented here is used compared to using the Wanninkhof (1992) parameterization. If instead one includes the gas exchange parameterization in a model, then the calculated fluxes differ by $\sim 35 \%$ between using this parameterization and that of Wanninkhof (1992). These differences suggest that the bubble component should be explicitly included in a range of marine biogeochemical calculations that incorporate air-sea gas fluxes.

Citation: Stanley, R. H. R., W. J. Jenkins, D. E. Lott III, and S. C. Doney (2009), Noble gas constraints on air-sea gas exchange and bubble fluxes, J. Geophys. Res., 114, C11020, doi:10.1029/2009JC005396.

\section{Introduction}

[2] In order to describe the marine component of the biogeochemical cycle of any gas, including $\mathrm{CO}_{2}$, one must be able to correctly quantify air-sea gas exchange [Doney et al., 2009]. Accurate representation of air-sea gas exchange processes in global climate carbon cycle models is clearly important [Doney et al., 2006], and air-sea gas exchange parameterizations are used in order to derive observational $\mathrm{CO}_{2}$ flux estimates from maps of surface ocean $\mathrm{pCO}_{2}$ [Takahashi et al., 1997, 2002]. Additionally, quantification of air-sea gas exchange fluxes is necessary for many types of biogeochemical research, such as in studies of euphotic zone oxygen measurements for determining net production [Craig and Hayward, 1987; Emerson, 1987; Spitzer and Jenkins, 1989; Hendricks et al., 2004; Reuer et al., 2007], ${ }^{3}$ He flux gauge measurements for determining new production [Jenkins, 1988a; Jenkins and Doney, 2003] and $\mathrm{O}_{2} / \mathrm{N}_{2}$ and atmospheric potential oxygen (APO) calculations [Keeling et al., 1993; McKinley et al., 2003; Bender et al., 2005].

[3] A variety of air-sea gas exchange parameterizations have been developed, primarily based on wind speed raised

\footnotetext{
${ }^{1}$ Department of Marine Chemistry and Geochemistry, Woods Hole Oceanographic Institution, Woods Hole, Massachusetts, USA.

Copyright 2009 by the American Geophysical Union. 0148-0227/09/2009JC005396\$09.00
}

to some power [Liss and Merlivat, 1986; Wanninkhof, 1992; Wanninkhof and McGillis, 1999; Nightingale et al., 2000], but such parameterizations have large uncertainties. Two recently published formulations [Ho et al., 2006; Sweeney et al., 2007] predict air-sea fluxes that are $25 \%$ to $33 \%$ lower than the most commonly used Wanninkhof [1992] wind speed squared function. Existing parameterizations have been based on data with either large spatial and temporal scales (such as the global marine radiocarbon budget) or on local spatial and short time scales (such as with tracer release experiments and eddy correlation measurements).

[4] Many of these parameterizations do not explicitly include air injection (bubble) processes. Bubble-mediated gas transfer may be significant, especially for less soluble gases and at higher wind speeds. It is difficult to estimate the total air injection flux from theoretical treatment of bubbles [Woolf and Thorpe, 1991; Keeling, 1993; Woolf, 1993] because of uncertainties in bubble size spectra, bubble dynamics, and depth distribution. A number of formulations of air injection have been proposed, with only some being validated with field evidence [Spitzer and Jenkins, 1989; Woolf, 1997; Asher and Wanninkhof, 1998; Hare et al., 2004; Woolf, 2005; Hamme and Emerson, 2006; Zhang et al., 2006; Fangohr and Woolf, 2007; McNeil and D'Asaro, 2007]. Uncertainties on these parameterizations are large, in part because of lack of appropriate field data and in part because bubble dynamics is a complicated 

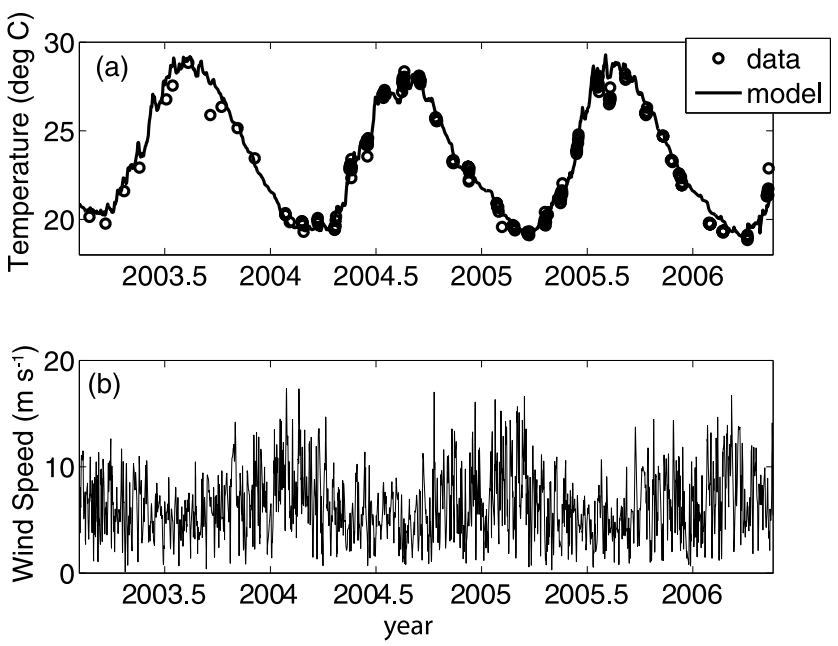

Figure 1. Physical forcing. (a) Mixed layer temperature as measured at the Bermuda Atlantic Time-series Study (BATS) site (circles) and as determined by the model (line) during the three year time series of noble gases. (b) Wind speed at BATS as determined from QuikSCAT satellite winds.

problem that may not lend itself to simple parameterizations [Woolf et al., 2007 and references therein]. One approach that has been used with success is to separate the bubble flux into two components, a component where bubbles dissolve completely and thus inject gases with atmospheric abundances and a component where bubbles dissolve only partially before emerging at the surface and thus fractionate the gases [Jenkins, 1988b; Spitzer and Jenkins, 1989; Keeling, 1993; Hamme and Emerson, 2006; McNeil and D'Asaro, 2007]. Although an idealization, this can prove useful in terms of affording parameterizations that can be easily applied and yet still give reasonable estimates of bubble fluxes.

[5] Noble gases are ideal tracers for investigating air-sea gas exchange because they are chemically and biologically inert. Additionally, they have a wide range of solubility (order of magnitude) and molecular diffusivity (factor of five) and thus respond differently to physical processes. The lighter noble gases have been used previously to estimate air-sea gas exchange parameters. Spitzer and Jenkins [1989] used a time series of $\mathrm{He}, \mathrm{Ne}$, and $\mathrm{Ar}$ in order to estimate the rate of diffusive gas exchange and air injection. More recently, Hamme and Emerson [2006] used a time series of $\mathrm{Ne}, \mathrm{Ar}$, and $\mathrm{N}_{2}$ to investigate the partitioning between completely trapped and partially dissolved bubbles. The study presented here expands on previous work by including measurements of $\mathrm{Kr}$ and $\mathrm{Xe}$. Including $\mathrm{Kr}$ and $\mathrm{Xe}$, the most soluble of the stable noble gases with the strongest solubility temperature dependence, increases the range of solubility of the suite of noble gases by a factor of four and the range of diffusivities by $20 \%$. Including $\mathrm{Kr}$ and $\mathrm{Xe}$ thus greatly improves the constraints on both diffusive gas exchange and on air injection fluxes [Stanley et al., 2006].

[6] Helium and neon, the least soluble noble gases, are sensitive to both diffusive gas exchange and to air injection (bubble) processes. Krypton and xenon, which are more soluble and have a stronger temperature dependence to solubility, respond primarily to thermal forcing and diffusive gas exchange. Argon has an intermediate behavior and, because it has very similar solubility and diffusivity to oxygen, is useful as an abiotic analog for oxygen. In our study region, the western subtropical Atlantic, surface water temperature changes by as much as $10^{\circ} \mathrm{C}$ on a seasonal basis, altering the solubility of gases significantly (Figure 1). Also, the mean wind speed changes from $5.1 \mathrm{~m} \mathrm{~s}^{-1}$ in the summer to $7.3 \mathrm{~m} \mathrm{~s}^{-1}$ in the winter. The degree to which the water column partial pressure of a gas is in disequilibrium with the atmosphere is controlled both by the gas exchange rate and the temperature dependence of the solubility. Measurements of the seasonal cycle of all the noble gases concurrently, therefore, allow separation and quantification of air-sea gas exchange processes.

[7] In this work, we use a three year time series at approximately monthly resolution of the five stable noble gases measured in the upper $400 \mathrm{~m}$ of the water column in the Sargasso Sea (western subtropical Atlantic) and a onedimensional time-dependent mixed layer model in order to construct a new empirical model of air-sea gas exchange. This parameterization is based on direct empirical data that has a characteristic timescale ranging from weeks to seasons - the timescale relevant to many biogeochemical cycles in the ocean - and explicitly includes bubble processes. Simple calculations of mixed layer depths and gas transfer velocities show that the timescale of gas exchange flux of the noble gases is on the order of weeks, comparable to the sampling period of the underlying observations. We present in this paper simple equations that can be used to estimate the fluxes due to diffusive gas exchange and bubbles; these two fluxes are closely coupled, and we demonstrate that the common practice of neglecting bubble processes results in biases in both diffusive gas exchange and net air-sea flux. We examine the sensitivity of the gas exchange parameters to the physical parameters in our 1-D model, to the choice of cost function, and to uncertainties in the solubilities of the noble gases. The parameters presented here are valid for use in environments with similar wind conditions to the Sargasso Sea $\left(0<\mathrm{u}_{10}<13 \mathrm{~m} \mathrm{~s}^{-1}\right)$ and that are similarly oligotrophic and thus have minimal surfactants.

\section{Methods}

\subsection{Sample Collection and Analysis}

[8] Samples for noble gases were collected approximately monthly at the Bermuda Atlantic Time series Study (BATS) site $\left(31.7^{\circ} \mathrm{N}, 64.2^{\circ} \mathrm{W}\right)$. A total of 34 stations were occupied, with typically 22 depths sampled for noble gases at each in the upper $400 \mathrm{~m}$. Water samples were transferred from Niskin bottles by gravity feeding through Tygon tubing into valved, $90 \mathrm{~cm}^{3}$ stainless steel sample cylinders. We extracted gases from the cylinders into aluminosilicate glass bulbs at an onshore laboratory within $24 \mathrm{~h}$ of sampling [Lott and Jenkins, 1998]. The aluminosilicate bulbs were attached to a dual mass spectrometric system and analyzed for $\mathrm{He}, \mathrm{Ne}$, $\mathrm{Ar}, \mathrm{Kr}$, and Xe according to Stanley et al. [2009]. In short, the noble gases in the water sample were chemically purified by sequential drawing through a two-stage water vapor cryotrap to remove water vapor, through a Pd catalyst to remove methane, and through Ti-Zr-Fe getters to remove 
reactive gases such as $\mathrm{O}_{2}, \mathrm{~N}_{2}$, and $\mathrm{H}_{2}$. The noble gases were then drawn onto two cryogenic traps [Lott, 2001]: a stainless steel cryogenic trap for $\mathrm{Ne}, \mathrm{Ar}, \mathrm{Kr}$ and $\mathrm{Xe}$ and an activated charcoal cryogenic trap for He. The cryogenic traps were selectively warmed, and the noble gases were sequentially released into a statically operated, Hiden Quadrupole Mass Spectrometer (QMS) for measurement by peak height manometry. Standardization of the system was accomplished using precisely known aliquots of atmospheric gases. Corrections are made for small nonlinearity and matrix effects. Reproducibility from duplicate field water samples is better than $0.3 \%$ for $\mathrm{Ar}, \mathrm{Kr}$, and $\mathrm{Xe}$ and approximately $1 \%$ for $\mathrm{He}$ and $\mathrm{Ne}$.

[9] Data are reported in terms of saturation anomaly, $\Delta$, which is defined as the percent departure from equilibrium

$$
\Delta=\left(\frac{C_{i, w}}{C_{i, e q}}-1\right) \times 100,
$$

where $C_{i, w}$ is the concentration of gas $i$ in the water and $C_{i, e q}$ is the concentration of gas $i$ that would be at equilibrium with water saturated atmosphere at the observed temperature and salinity and one atmosphere total pressure (i.e., the solubility value). Positive (negative) saturation anomalies reflect that the gas is supersaturated (undersaturated). We incorporate into our calculations and error analysis the estimated solubility uncertainties for the noble gases in seawater, which are $\pm 0.5 \%$ for He [Weiss, 1971], $\pm 0.13 \%$ for $\mathrm{Ne}$ [Hamme and Emerson, 2004], $\pm 0.13 \%$ for Ar [Hamme and Emerson, 2004], $\pm 1 \%$ for Kr [Weiss and Kyser, 1978], and $\pm 1.5 \%$ for Xe [Wood and Caputi, 1966]. Hamme and Emerson [2004] found a 1\% offset in Ne solubility values of Weiss [1971]. Since Weiss [1971] experimentally determined the He solubility in a similar fashion as $\mathrm{Ne}$, we assumed similar systematic biases, and hence scaled the He solubility value of Weiss [1971] according to Hamme and Emerson's [2004] correction for $\mathrm{Ne}$.

\subsection{Description of One-Dimensional Vertical Upper Ocean Model}

[10] In order to use the noble gas data to improve parameterizations of air-sea gas exchange, we use a onedimensional numerical model [Price et al., 1986], extended to incorporate gases [Spitzer and Jenkins, 1989; Stanley et $a l ., 2006]$, to explore the sensitivity of air-sea gas exchange parameters to noble gas measurements. The 1-D model is forced with high-frequency, synoptic atmospheric physical forcing [Doney, 1996] using six hourly NCEP reanalysis heat fluxes [Kalnay et al., 1996] and 12 hourly QuikSCAT winds. QuikSCAT winds were chosen rather than NCEP winds because the QuikSCAT wind record more closely matched a wind record from the nearby Bermuda Testbed Mooring (BTM) [Dickey et al., 1998]. The correlation coefficient, $r^{2}$, between the QuikSCAT and BTM wind records was 0.82 whereas the correlation coefficient, $r^{2}$, between NCEP and BTM wind records was 0.64. The BTM record was not used directly because of gaps occurring when the mooring was not deployed. Additionally, a significant advantage of using QuikSCAT winds is to make our parameterization applicable for other applications since satellite data are more frequently available than mooring data. The vertical attenuation of solar radiative heating in the model is governed by a Jerlov Type 1A profile.

[11] The annually averaged NCEP net air-sea heat flux for this site is negative, reflecting net ocean cooling. Lateral advective heat convergence probably balances the local heat budget over longer than annual timescales. To compensate for this effect, we add to the model upper ocean a temporally uniform, lateral positive heat flux of order $50 \mathrm{~W} \mathrm{~m}^{-2}$, calculated to balance the sum of the NCEP heat fluxes. There is also an effective heat convergence in this model associated with Ekman pumping. We computed the Ekman pumping from the four day low-pass filtered local wind stress curl derived from the NCEP reanalysis data. The resultant vertical velocity is tapered to zero at the bottom of the model domain, in approximate concordance with the Sverdrup relation. We can compensate for this by removing approximately $20 \mathrm{~W} \mathrm{~m}^{-2}$ from the upper water column.

[12] The magnitude of the required Ekman heat convergence compensation term $(E k m)$ depends on the evolution of model temperature and thus is difficult to calculate explicitly. We therefore treat $E \mathrm{~km}$ as a tunable physical model parameter that is adjusted to maintain a long-term net zero heat balance. Similarly, we treat the depth $(Z)$ over which we uniformly distribute the total heat offset (sum of lateral and Ekman compensation terms of about $+50-20=$ $30 \mathrm{~W} \mathrm{~m}^{-2}$ ) as a tunable model parameter. Additionally, the vertical eddy diffusivity below the mixed layer in the model, $K_{z}$ is also treated as a tunable model parameter.

[13] We are required to simulate the sea surface temperature accurately in order to model the gases correctly. Hence, to compensate for subannual model errors, simulated surface temperature is restored every $6 \mathrm{~h}$ to a smoothed, interpolated record of the BATS sea surface temperature, with a restoring constant of $75 \mathrm{~W} \mathrm{~m}^{-2} \operatorname{deg~} \mathrm{C}^{-1}$. The model has periods of both positive and negative temperature errors on these timescales, and the net effect of restoring on the model heat budget over the full simulation is small.

[14] Ensemble runs $(\mathrm{n} \sim 100)$ and a cost function based on the root mean square difference (RMSD) between model and data temperature and salinity (with data from the BATS bottle casts) were used to determine optimal values for the three tunable physical parameters $\left(E k m, Z, K_{z}\right)$. A wide range of physical parameters was examined: $2 \times 10^{-5}<K_{z}<2 \times$ $10^{-4} \mathrm{~m}^{2} \mathrm{~s}^{-1}, 1<E k m<30 \mathrm{~W} \mathrm{~m}^{-2}$ and $10<Z<125 \mathrm{~m}$. The parameters work in concert, and thus several combinations of parameter values yielded an almost equivalent cost function value. Subsequent work used primarily a reference case with the lowest cost function, i.e, $K_{z}=5 \times 10^{-5} \mathrm{~m}^{2} \mathrm{~s}^{-1}$, $E k m=18 \mathrm{~W} \mathrm{~m}^{-2}$, and $Z=50 \mathrm{~m}$, but we also explored the sensitivity of our gas exchange results to alternate sets of physical parameters.

[15] The estimated diffusivities ( $K_{z}$ ranging from $4 \times 10^{-5}$ to $6 \times 10^{-5} \mathrm{~m}^{2} \mathrm{~s}^{-1}$ ) are comparable or lower than values found in a previous 1-D modeling study for the Sargasso Sea [Spitzer and Jenkins, 1989] but are somewhat higher than the canonical diapycnal diffusivity of $\sim 2 \times 10^{-5} \mathrm{~m}^{2} \mathrm{~s}^{-1}$ computed from tracer release experiments in the permanent main thermocline [Ledwell et al., 1993, 1998]. However, the model sensitivity to $K_{z}$ is primarily due to diffusion-driven changes in the subannual evolution of the temperature field in the shallower seasonal thermocline, where higher diffusivities could be expected episodically in the stratified 
region below the base of the mixed layer proper due to surface forcing [Large et al., 1994]. Diapycnal diffusivity estimates from microturbulence techniques tend to confirm the low tracer-based values in the permanent thermocline, though there is evidence for elevated upper ocean diffusivities similar to our model estimate near subtropical frontal regions [Polzin et al., 1996]. The Ekman heat flux $(E k m)$ and depth $Z$ are comparable to values used in previous modeling studies for this region [Doney, 1996].

\subsection{Gas Exchange Parameterization}

[16] We formulated the diffusive gas exchange flux component using the Wanninkhof [1992] relationship, where the diffusive gas transfer velocity varies with wind speed squared, but with a scaling parameter to adjust the magnitude of the flux. Specifically, the diffusive gas exchange flux, $F_{G E}$, in $\mathrm{mol} \mathrm{m} \mathrm{m}^{-2} \mathrm{~s}^{-1}$, is modeled according to the equation

$$
F_{G E}=\gamma_{G} \cdot 8.6 \times 10^{-7}\left(\frac{S c}{660}\right)^{-0.5} u_{10}^{2}\left(C_{i, e q}-C_{i, w}\right),
$$

where $\gamma_{\mathrm{G}}$ is an order one, tunable model parameter that scales the magnitude of diffusive gas exchange, $S c$ is the Schmidt number, $u_{10}$ is the wind speed in $\mathrm{m} \mathrm{s}^{-1}$ at a height of $10 \mathrm{~m}$ above the sea surface, $C_{i, e q}$ is the concentration of the gas $i$ at equilibrium $\left(\mathrm{mol} \mathrm{m}^{-3}\right)$, and $C_{i, w}$ is the concentration of the gas $i$ in the water $\left(\mathrm{mol} \mathrm{m}^{-3}\right)$. In this study, the noble gases were used to constrain $\gamma_{\mathrm{G}}$ to equal $0.97 \pm 0.14$. All uncertainties are reported as one standard deviation $(1 \sigma)$.

[17] The air injection flux is separated into two components [Fuchs et al., 1987; Jenkins, 1988b; Spitzer and Jenkins, 1989; Hamme and Emerson, 2006]. This is a simplification of the undoubtedly complex nature of bubble processes but is useful as it characterizes the two endmembers. The first component comprises completely trapped bubbles - bubbles that dissolve completely and thus inject gases with atmospheric abundances. The flux due to completely trapped bubbles, $F_{c}$, is parameterized using the whitecap coverage parameterization of Monahan and Torgersen [1990] and the air entrainment velocity estimate of Keeling [1993]. The flux, in $\mathrm{mol} \mathrm{m}^{-2} \mathrm{~s}^{-1}$, is parameterized as

$$
F_{C}=A_{c}\left(u_{10}-2.27\right)^{3} \frac{P_{i, a}}{R T},
$$

where $A_{c}$ is a tunable model parameter which includes constants from the air entrainment velocity and whitecap formulations $\left(\mathrm{s}^{2} \mathrm{~m}^{-2}\right), P_{i, a}$ is the partial pressure of gas $i$ in the atmosphere calculated from the fractional abundance of the gas and the variable total atmospheric pressure $(\mathrm{Pa})$, $R$ is the gas constant $\left(8.31 \mathrm{~m}^{3} \mathrm{~Pa} \mathrm{~mol}^{-1} \mathrm{~K}^{-1}\right)$, and $T$ is the temperature $(\mathrm{K})$. In this study, noble gases were used to constrain $A_{c}$ to equal $9.1( \pm 1.3) \times 10^{-11} \mathrm{~s}^{2} \mathrm{~m}^{-2}$.

[18] The second component comprises bubbles that only partially dissolve. These bubbles, which are often larger, are injected downward by wave action but then rise to the surface. During the transit to the surface, gases are exchanged across the bubble surface, and thus the injected gases are fractionated according to their permeation rate [Keeling, 1993; Stanley et al., 2006]. The partially trapped bubble flux therefore depends on the solubility and diffu- sivity of the gas, as well as the depth to which the bubble is injected. The flux is given in mol m $\mathrm{m}^{-2} \mathrm{~s}^{-1}$ by

$$
F_{P}=A_{p} \cdot\left(u_{10}-2.27\right)^{3} \alpha_{i}\left(\frac{D_{i}}{D_{\mathrm{o}}}\right)^{\frac{2}{3}} \frac{\left(P_{i, b}-P_{i, w}\right)}{R T},
$$

where $A_{p}$ is a tunable model parameter controlling the magnitude of the diffusive gas exchange flux $\left(\mathrm{s}^{2} \mathrm{~m}^{-2}\right), \alpha$ is the Bunsen solubility coefficient of gas $i$ (dimensionless), $D_{i}$ is the diffusivity coefficient of gas $i\left(\mathrm{~m}^{2} \mathrm{~s}^{-1}\right), D_{o}$ is a normalization factor equal to 1 which is included in order to simplify the units $\left(\mathrm{m}^{2} \mathrm{~s}^{-1}\right), P_{i, b}$ is the pressure of gas $i$ in the bubble (Pa) and $P_{i, w}$ is the partial pressure of gas $i$ in the water (Pa). $P_{i, b}$ is approximated by

$$
P_{i, b}=X_{i}\left(P_{\mathrm{atm}}+\rho g z_{b u b}\right),
$$

where $X_{i}$ is the mole fraction of gas $i$ in dry air, $P_{\text {atm }}$ is the atmospheric pressure of dry air $(\mathrm{Pa}), \rho$ is the density of water $\left(\mathrm{kg} \mathrm{m}^{-3}\right), g$ is the gravitational acceleration $\left(9.81 \mathrm{~m} \mathrm{~s}^{-2}\right)$, and $z_{b u b}$ is the depth to which the bubble sinks (m), which is parameterized, according to Graham et al. [2004]

$$
z_{b u b}=\left(0.15 \cdot u_{10}-0.55\right) .
$$

[19] For a detailed explanation of the rationale behind this parameterization see Stanley et al. [2006]. In this study, noble gases were used to constrain $A_{p}$ to equal $2.3( \pm 1.5) \times$ $10^{-3} \mathrm{~s}^{2} \mathrm{~m}^{-2}$. Note that even though the uncertainty on $A_{p}$ is large, since the partially trapped bubble flux is only a small contribution ( 0 to $10 \%$ of the total air injection flux), the uncertainty on the total air injection flux is only $\pm 29 \%$. Equation (4) can be rewritten in a form that is easier to apply when the concentration of the gas in water is measured:

$$
F_{P}=A_{p} \cdot\left(u_{10}-2.27\right)^{3} \alpha_{i}\left(\frac{D_{i}}{D_{o}}\right)^{2 / 3} \frac{X_{i} P_{\mathrm{atm}}}{R T}\left(1+\frac{\rho g z_{b u b}}{P_{\mathrm{atm}}}-\frac{C_{i, w}}{C_{i, e q}}\right) .
$$

\subsection{Inverse Approach}

[20] We embedded the 1-D gas exchange model in a nonlinear optimization scheme. A cost function based on model-data differences of noble gas surface saturation anomalies and subsurface concentrations was used to determine the values for adjustable parameters controlling the magnitude of these three types of gas exchange fluxes: diffusive gas exchange magnitude $\left(\gamma_{\mathrm{G}}\right)$, completely trapped bubbles $\left(A_{c}\right)$, and partially trapped bubbles $\left(A_{P}\right)$. These parameters can be applied to calculate the flux of any gas of interest, e.g., $\mathrm{CO}_{2}$, $\mathrm{O}_{2}, \mathrm{~N}_{2} \mathrm{O}$, etc. To compute the cost function, the model is subsampled at the depth and time of the observations.

[21] The cost function is equal to

$$
\begin{aligned}
C F= & \frac{a_{1}}{N_{\Delta}} \sum_{i=1}^{5}\left(\sum_{j=1}^{N_{\Delta}} \frac{\left(\Delta_{\bmod , i, j}-\Delta_{o b s, i, j}\right)^{2}}{\sigma_{\Delta i, j}^{2}}\right) \\
& +\frac{a_{2}}{N_{\text {conc }}} \sum_{i=1}^{5}\left(\sum_{j=1}^{\text {Nconc }} \frac{\left([X]_{\bmod , i, j}-[X]_{o b s, i, j}\right)^{2}}{\sigma_{c o n c, i, j}^{2}}\right)
\end{aligned}
$$


where $a_{1}$ and $a_{2}$ are constants used to make the two components have approximately equal contributions to the cost function, $i$ is a counter for each of the five gases, $j$ is a counter for each of the measurements, $N_{\Delta}$ is the total number of monthly surface saturation anomaly measurements (i.e., 34), $\Delta_{m o d, i, j}$ and $\Delta_{o b s, i, j}$ are the monthly surface saturation anomalies of the gases in either the model or observations, $\sigma_{\Delta i, j}$ are the uncertainties in the monthly average surface saturation anomaly measurements, $N_{\text {conc }}$ is the total number of concentration measurements, $[X]_{\text {mod,i,j }}$ and $[X]_{o b s, i, j}$ are the concentrations of the gases in either the model or in the observations, and $\sigma_{c o n c, i, j}$ are the uncertainties in the concentration measurements.

[22] The first component reflects the differences between the model and data's mixed layer depth-averaged monthly surface saturation anomalies. We use average monthly values rather than point-to-point depth comparisons of mixed layer saturation anomaly between our model and data in order to avoid overemphasizing the winter months, which have more data in the mixed layer simply because the mixed layer is deeper, and to avoid underemphasizing the summer months, which only have a few data points in the mixed layer since the mixed layer is shallow. The saturation anomalies are weighted by the combined uncertainty of the sampling collection and analytical uncertainty, the estimated uncertainty in the solubility values for the particular gas, and the standard error of multiple determinations within the mixed layer in the given month, all added in quadrature.

[23] The second component of the cost function is constructed from the difference between the model and observed concentrations below the mixed layer. We use concentrations here, rather than saturation anomalies, because erroneously high (low) temperatures in the model below the mixed layer result in erroneously high (low) saturation anomalies. The model does not achieve precisely the correct thermal structure below the mixed layer (RMSD of temperature in upper $200 \mathrm{~m}=0.42^{\circ} \mathrm{C}$ ); by using concentrations in our cost function, we compare the total inventory of the gases in the water column, and thus temperature effects are not as significant. Further, it is the seasonal changes in inventory (not subsurface anomalies) that provide the observational constraint on the temporally integrated gas fluxes.

[24] In the reference case, the surface saturation anomaly and the deep concentration components of the cost function are scaled using $a_{1}$ and $a_{2}$ such that they contribute in approximately equal proportions. We examined the sensitivity of the results to shifting the balance between these two parts of the cost function as well as adding in a third component that reflected the seasonal differences in the noble gas saturation anomalies.

\section{Results and Discussion}

\subsection{Noble Gas Signatures}

[25] Plots of the three year time series of the five noble gases in the upper $160 \mathrm{~m}$ of the water column (Figure 2a) and in the mixed layer (Figure 3 ) reveal that the gases fall into two distinct groups. Helium and neon, relatively insoluble, are always a few percent supersaturated in the upper ocean because of bubble processes. The main factor affecting the fluxes of $\mathrm{He}$ and $\mathrm{Ne}$ is that air injection brings gas into the ocean and then diffusive gas exchange fluxes it out. Helium and Ne do not show seasonal structure because these gases have only a weak temperature dependence of solubility. The He and Ne saturation anomaly data are noisy due to bubbles inadvertently trapped during sample collection. Laboratory experiments were used to determine that the supersaturation due to these bubbles trapped during collection was $1.2 \pm 0.8 \%$ for $\mathrm{He}$ and $0.97 \pm 0.7 \%$ for $\mathrm{Ne}$, and the data were corrected accordingly [Stanley, 2007].

[26] Argon, krypton, and xenon form the second group. These gases show maximal saturation anomalies in the summer, especially below the mixed layer, because of their much stronger solubility temperature dependence. They are less soluble in warmer water and thus in the summer become supersaturated, driving a seasonal diffusive gas exchange flux out of the water during the heating seasons and the reverse during cooling seasons. The relative magnitudes of the supersaturation of these gases correlate with the temperature dependency of solubility; Xe has the largest summer supersaturation and Ar the smallest.

[27] Figure $2 \mathrm{~b}$ presents the model results and illustrates the very good agreement between the model and the data. The largest discrepancy between model and data occurs in July and August 2004, due to the passage of an eddy. Our results are not significantly affected by the inclusion or omission of data from these months.

[28] The values of the gas exchange parameters are presented in Table 1. We present the reference case as well as a sensitivity study where we examined the value of the parameters determined in a number of different cases - different physical parameters, different time periods, different balance of cost function, a systematic shift in the solubility values of the heavier noble gases, addition of a lateral flux of gases, etc.

\subsection{Gas Fluxes: Diffusive Gas Exchange and Air Injection}

[29] We determine the optimal magnitude of the diffusive gas exchange parameter $\gamma_{\mathrm{G}}$ (as defined in equation (2)) to be $0.97 \pm 0.14$, of $A_{C}$ (as defined in equation (3)) to be 9.1 $( \pm 1.3) \times 10^{-11} \mathrm{~s}^{2} \mathrm{~m}^{-2}$ and of $A_{P}$ (as defined in equation (4)) to be $2.3( \pm 1.5) \times 10^{-3} \mathrm{~s}^{2} \mathrm{~m}^{-2}$. Because the meanings of $A_{C}$ and $A_{P}$ are not immediately intuitive, we have listed in Table 1 the air injection flux of total gas corresponding to these parameter values at a wind speed of $7 \mathrm{~m} \mathrm{~s}^{-1}$ (the average wind speed at BATS). We constrain the magnitude of the diffusive gas exchange to have a $1 \sigma$ uncertainty of $\pm 14 \%$ and the total air injection flux to have a $1 \sigma$ uncertainty of $\pm 29 \%$.

[30] The model can be used to examine the relative contribution of diffusive gas exchange fluxes versus air injection fluxes for the different gases (Figure 4). We find that the air injection flux is significant for all the noble gases, even the soluble ones, and thus should be explicitly included in models and calculations, especially for gases with solubilities equal to or less than that of Xe, such as $\mathrm{O}_{2}$ and $\mathrm{N}_{2}$. For $\mathrm{He}$, the least soluble gas studied, the air injection flux is in large part balanced by the diffusive gas exchange flux. For Ar, which is of interest since it responds physically in a similar manner as $\mathrm{O}_{2}$, the air injection flux in the winter (when wind speeds are greater) is also nearly 
(a) Data
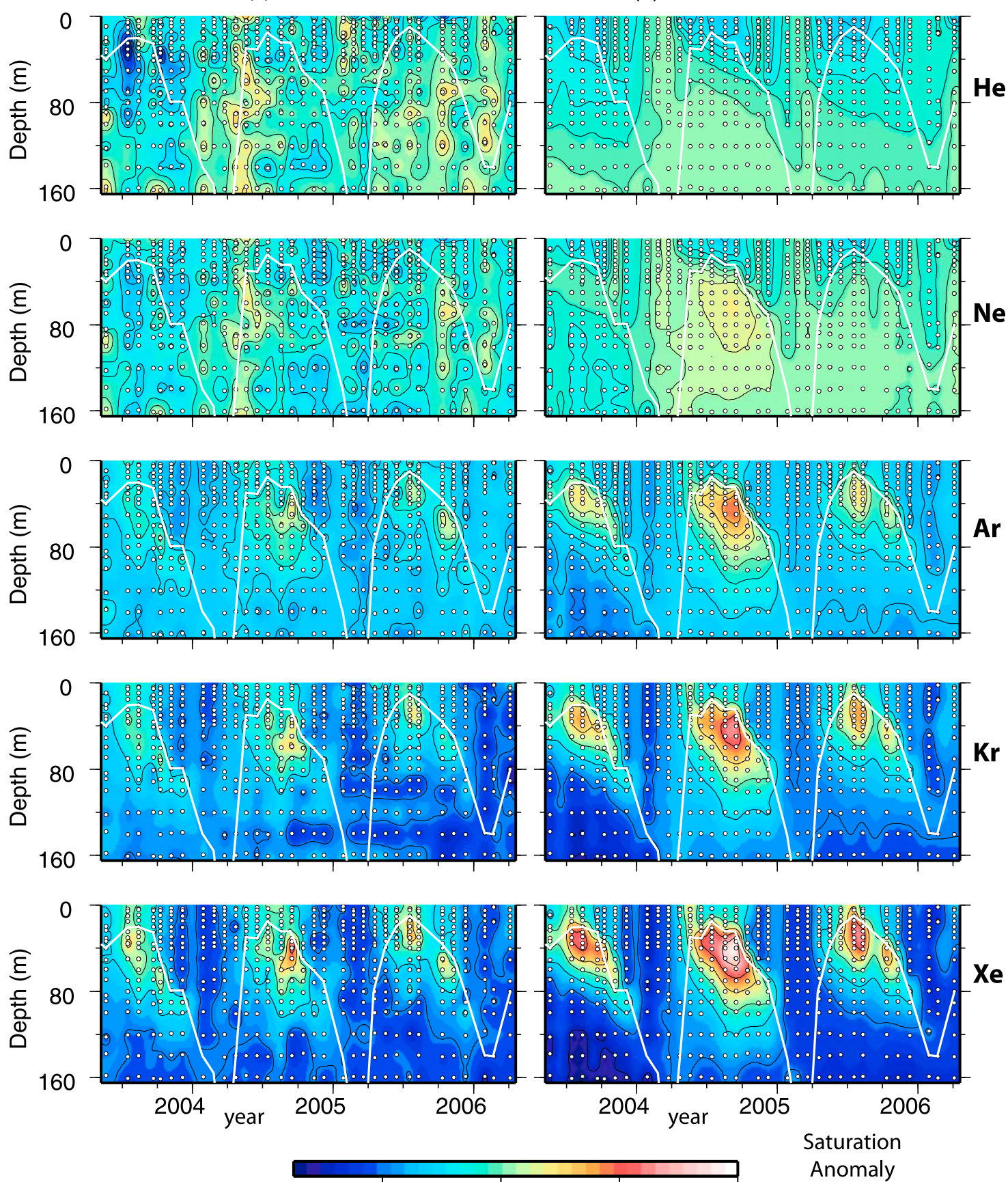

0
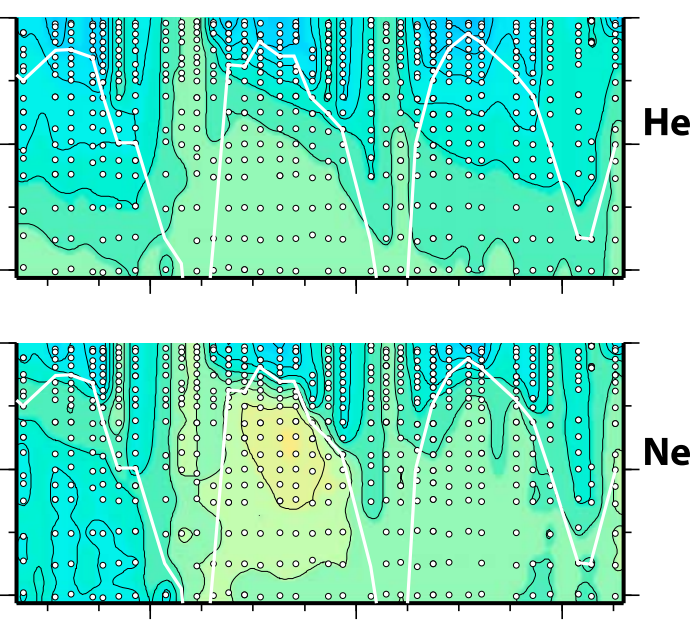

Ne

\section{He}

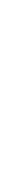



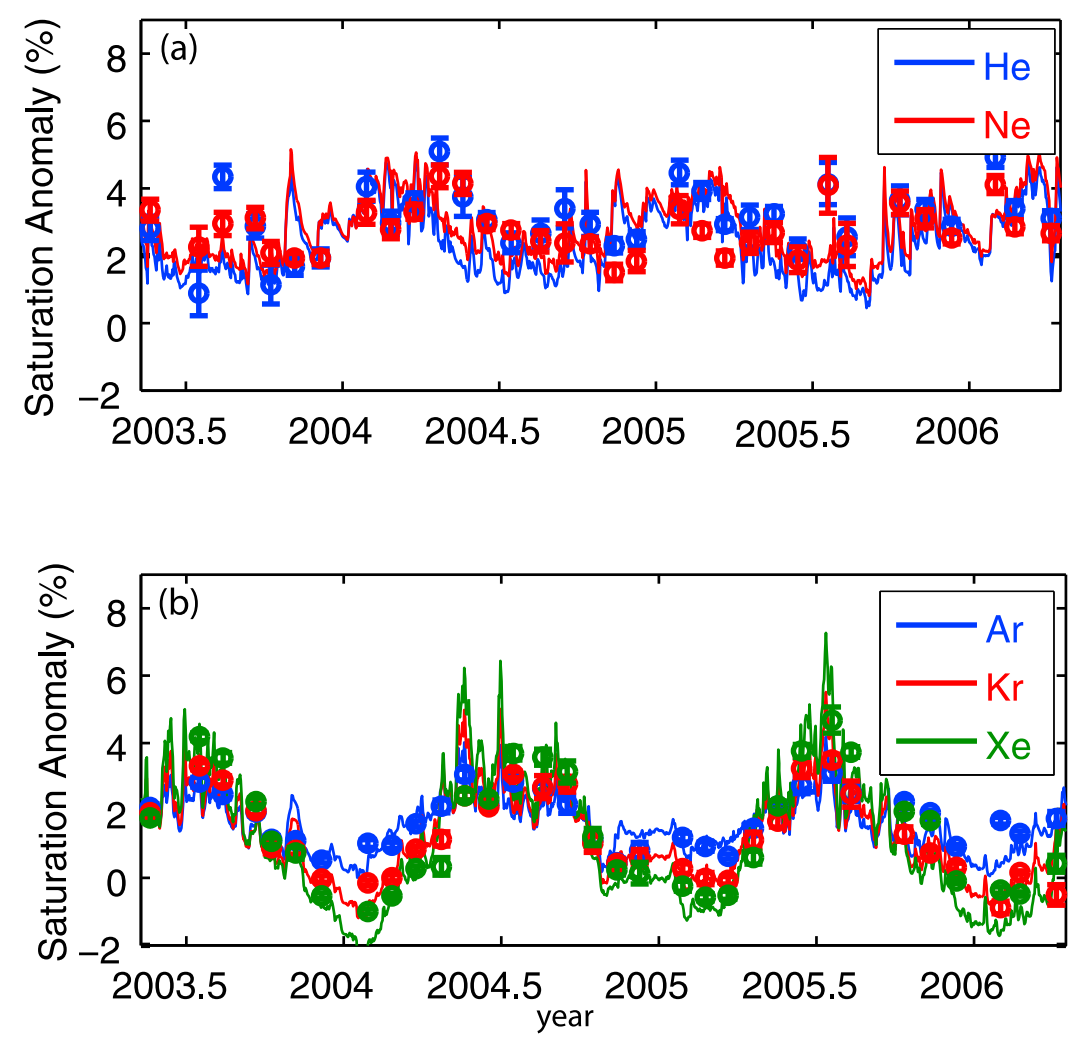

Figure 3. Saturation anomalies in the surface ocean (a) for helium and neon and (b) for argon, krypton, and xenon. In both the model and the data, $\mathrm{He}$ and $\mathrm{Ne}$ are always a few percent supersaturated and show little seasonal variation. In contrast, $\mathrm{Ar}, \mathrm{Kr}$, and $\mathrm{Xe}$ show a distinct seasonal pattern with $\mathrm{Xe}$ being the most supersaturated in the summer. Circles represent the average of multiple measurements within the mixed layer ( $\mathrm{N}_{\mathrm{avg}}=12$ with a range from 4 to 25 depending on the mixed layer depth). The error bars reflect the standard error of the mean. Lines denote model results.

[31] Most (>95\%) of the bubble flux stems from bubbles that are completely trapped, a result that differs from that of Hamme and Emerson [2006] who used $\mathrm{Ne}, \mathrm{N}_{2}$, and Ar data to determine roughly even partitioning of the flux between partial and completely trapped bubbles. We performed a sensitivity study in which we ran the model five times, using approximately the same total air injection flux but a differing proportion of partial to complete trapping flux, with the fraction of completely trapped bubbles, $f A_{c}$, ranging from 0 to $100 \%$. This study illustrated that the fraction of completely versus partially trapped bubbles is particularly sensitive to the saturation anomaly of $\mathrm{Kr}$ and $\mathrm{Xe}$ (Figure 5). Since partial trapping is proportional to the solubility of the noble gases and the heavier gases are more soluble, the heavier gases have a larger fraction of partial to complete trapping and are more sensitive to the fraction of partial to complete trapping. At the moment, given the solubility uncertainty in Xe, we cannot use Xe to constrain well the fraction of complete versus partial trapping. However, if the solubility uncertainties in Xe were reduced, then Xe could offer a powerful tool for better distinguishing between partial and complete trapping.

[32] We used the model to estimate the effect of bubbles on the flux of $\mathrm{CO}_{2}$. In the wintertime, the contribution to $\mathrm{CO}_{2}$ from the bubble flux on average is $5 \%$ of the diffusive gas exchange flux. During occasional events, the contribution of the bubble flux can be $30 \%$ to $60 \%$ of the diffusive gas exchange flux. This supports recent suggestions that bubble fluxes may be important under some conditions for $\mathrm{CO}_{2}$ [Blomquist et al., 2006].

[33] The gas exchange parameters act in concert to some extent. Plots of the cost function as a function of the parameters show a narrow valley. A low cost function can be obtained when both air injection and diffusive gas exchange increase (Figure 6a) or when they both decrease. There is also a play-off between the two air injection parameters. If complete trapping increases than partial trapping can decrease and the cost function will remain low (Figure 6b). Because of this covariation between the air injection parameters, it is difficult to precisely constrain the relative contributions of partially trapped and completely trapped bubbles from the data we have presently.

\subsection{Comparisons With Other Parameterizations}

[34] The diffusive gas exchange parameter, $\gamma_{\mathrm{G}}$, is within errors of the commonly used Wanninkhof [1992, hereinafter W92] quadratic wind speed relationship. However, that does not mean that the fluxes predicted by the parameterization presented here are comparable to those estimated from the W92 relationship. Rather, since the diffusive gas flux is coupled to the air injection flux, one should compare the net flux calculated from the formulation presented here to the net flux calculated from other parameterizations. To this end, we ran the model with the W92 parameterization 
Table 1. Gas Exchange Parameters From Ensemble of Runs That Explore the Sensitivity of the Parameters

\begin{tabular}{|c|c|c|c|c|c|}
\hline$\gamma_{\mathrm{G}}$ & $\operatorname{Ac}\left(\times 10^{11}\right)$ & $\mathrm{Ap}\left(\times 10^{3}\right)$ & $\begin{array}{c}\text { Total Air } \\
\text { Injection Flux } \\
\left(\times 10^{7} \mathrm{~mol} \mathrm{~m}^{-2} \mathrm{~s}^{-1}\right)\end{array}$ & $\begin{array}{c}\text { Fraction } \\
\text { Completely Trapped } \\
\text { Bubbles (\%) }\end{array}$ & Notes \\
\hline \multicolumn{6}{|l|}{ Base Case } \\
\hline 0.97 & 9.09 & 2.29 & 3.99 & 97 & \\
\hline \multicolumn{6}{|l|}{ Modeling Uncertainites } \\
\hline \multicolumn{6}{|c|}{ Different Physical Parameters } \\
\hline 1.00 & 9.35 & 2.28 & 4.10 & 97 & $\begin{array}{l}\text { Physical parameters: } \mathrm{Kz}=6 \times 10^{-5} \text {, } \\
\qquad \mathrm{Ekm}=20, Z=50\end{array}$ \\
\hline 0.94 & 8.79 & 2.27 & 3.85 & 97 & $\begin{array}{l}\text { Physical parameters: } \mathrm{Kz}=4 \times 10^{-5} \text {, } \\
\qquad \mathrm{Elkm}=16, \mathrm{Z}=50\end{array}$ \\
\hline 1.05 & 9.92 & 1.98 & 4.35 & 98 & $\begin{array}{l}\text { Physical parameters: } \mathrm{Kz}=8 \times 10^{-5} \text {, } \\
\qquad \mathrm{Ekm}=22, \mathrm{Z}=50\end{array}$ \\
\hline 0.91 & 8.56 & 2.12 & 3.75 & 97 & $\begin{array}{l}\text { Physical parameters: } \mathrm{Kz}=3 \times 10^{-5} \text {, } \\
\qquad \mathrm{Ekm}=12, \mathrm{Z}=50\end{array}$ \\
\hline 0.83 & 7.79 & 2.10 & 3.42 & 97 & $\begin{array}{l}\text { Physical parameters: } \mathrm{Kz}=2 \times 10^{-5} \text {, } \\
\qquad \mathrm{Ekm}=18, \mathrm{Z}=76^{\mathrm{b}}\end{array}$ \\
\hline 1.11 & 10.43 & 1.95 & 4.58 & 98 & $\begin{array}{l}\text { Physical parameters: } \mathrm{Kz}=1 \times 10^{-4} \text {, } \\
\qquad \mathrm{Ekm}=18, \mathrm{Z}=50^{\mathrm{b}}\end{array}$ \\
\hline \multicolumn{6}{|c|}{ Without Temperature Restoring } \\
\hline 0.90 & 8.30 & 2.29 & 3.66 & 97 & Temperature is not restored \\
\hline \multicolumn{6}{|c|}{ Balance Between Surface and Deep } \\
\hline 0.95 & 8.84 & 2.59 & 3.87 & 97 & $\begin{array}{l}\text { Surface sat anomaly weighted twice } \\
\text { the deep concentration }\end{array}$ \\
\hline 1.01 & 9.59 & 1.70 & 4.21 & 98 & $\begin{array}{l}\text { Surface sat anomaly weighted half } \\
\text { the deep concentration }\end{array}$ \\
\hline \multicolumn{6}{|c|}{$\begin{array}{l}\text { Including Seasonal Amplitude } \\
\text { in Cost Function }\end{array}$} \\
\hline 1.05 & 8.42 & 3.22 & 3.69 & 96 & $\begin{array}{l}\text { Mixed layer cost contains } 50 \% \text { absolute } \\
\text { magnitude and } 50 \% \text { seasonal amplitude }\end{array}$ \\
\hline 1.00 & 8.84 & 2.84 & 3.87 & 97 & $\begin{array}{l}\text { Mixed layer cost contains } 75 \% \text { absolute } \\
\text { magnitude and } 25 \% \text { seasonal amplitude }\end{array}$ \\
\hline \multicolumn{6}{|c|}{$\begin{array}{l}\text { Time Periods for Model-Data } \\
\text { Comparison }\end{array}$} \\
\hline 0.96 & 7.99 & 2.35 & 3.50 & 97 & Only used data from 2003.35 to 2004.35 \\
\hline 0.84 & 6.94 & 2.91 & 3.04 & 95 & Only used data from 2004.35 to 2005.35 \\
\hline 1.04 & 11.76 & 5.36 & 5.16 & 95 & Only used data from 2005.35 to 2006.35 \\
\hline
\end{tabular}

Solubility Uncertainties

Systematic Shift in Solubility

of $\mathrm{Kr}$ and $\mathrm{Xe}$

0.89

1.03

5.63

3.26

92

4.49

100

0.89

10.25

0

3.32

92

1.03

$7.57 \quad 5.58$

4.44

100

Lateral Heat Uncertainties

Adding in Lateral Gas

Compensation Term

0.90

$8.15 \quad 5.90$

3.57

93

$9.01 \quad 2.53$

3.96

Xe solubility $=98.5 \%$ of
Wood and Caputi $[1966]$
Xe solubility $=101.5 \%$ of
Wood and Caputi $[1966]$
Kr solubility $=99 \%$ of
Weiss and Kyser $[1978]$
Kr solubility $=101 \%$ of
Weiss and Kyser $[1978]$

0.96

2.53

$97 \%$

Lateral gases scaled by SOC climatology heat flux imbalance [Grist and Josey, 2003] Lateral gases scaled by the OAFlux heat flux imbalance [Yu and Weller, 2007]

\footnotetext{
${ }^{\mathrm{a}}$ Total air injection flux was calculated assuming a wind speed of $7 \mathrm{~m} \mathrm{~s}^{-1}$.

${ }^{\mathrm{b}}$ The physical parameters for these runs are not realistic in the context of this model at this location. They are included solely to show that even with extreme values of $K_{z}$, the diffusive gas exchange parameter differs by only $\pm 15 \%$.
}

and compared the net flux of Ar from the W92 model run with the net flux of Ar from our parameterization (Figure 7a). We consider Ar because it has very similar solubility and diffusivity to $\mathrm{O}_{2}$ and thus is of interest to many researchers. We also ran the model with the Sweeney et al. [2007, hereinafter S07] parameterization. Since the results with $\mathrm{S} 07$ are similar to that of W92, only the W92 results are shown. Neither W92 nor S07 explicitly include air injection processes.
[35] The net Ar flux from the formulation presented in this study (Figure 7a, black curve) is significantly larger (more positive) in the wintertime and smaller (less negative) in the summertime than the net Ar flux when the model is run with W92 (Figure 7a, red curve) or S07 (not shown). This is because the air injection flux, which scales as the cube of the wind speed, is always into the ocean. In the winter, the air injection flux works in the same direction as 


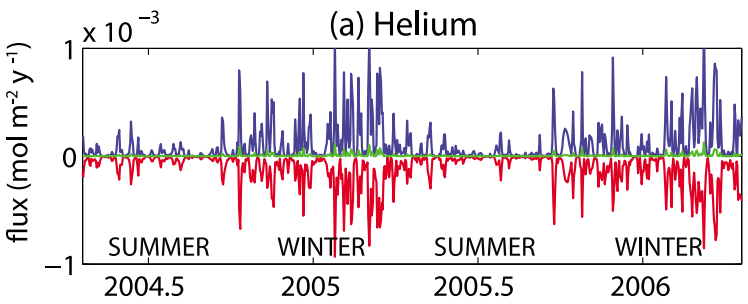

(b) Argon (Similar to $\mathrm{O}_{2}$ )
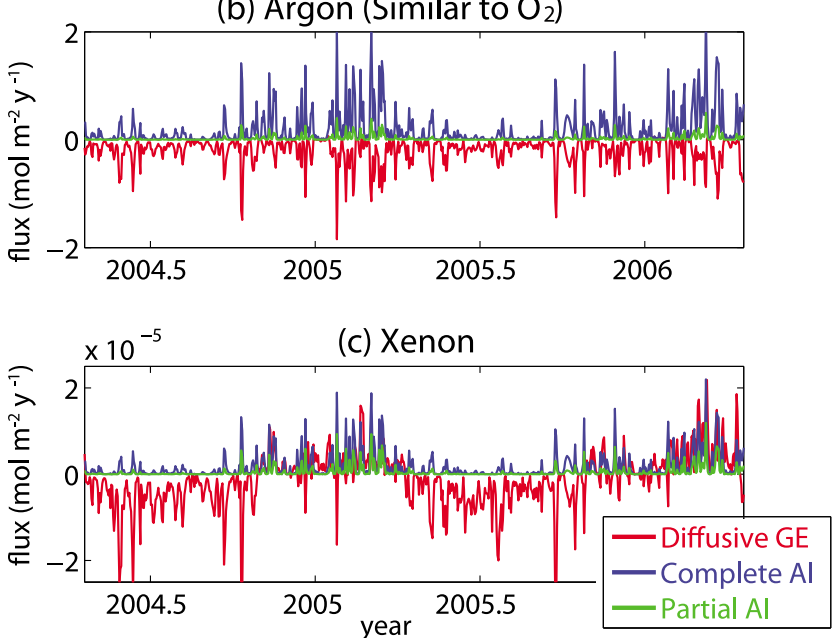

Figure 4. Diffusive gas exchange and air injection fluxes for three of the noble gases. Diffusive gas exchange fluxes (red), completely trapped bubble fluxes (blue), and partially trapped bubble fluxes (green) for (a) He, (b) Ar, and (c) Xe as calculated by the model. Positive (negative) fluxes represent fluxes of gas into (out of) the ocean. The bubble fluxes are largest in the wintertime since the winds are strongest then. Bubble fluxes are significant in the winter for all the gases, even for the more soluble gases such as $\mathrm{Ar}$ (and thus $\mathrm{O}_{2}$ ) and $\mathrm{Xe}$.

the diffusive gas exchange flux whereas in the summer, the air injection flux works in the opposite direction as the diffusive gas exchange flux. Notably, when the model is run with W92 (Figure 7b) or S07, the model does not match the observed wintertime Ar supersaturation. Since W92 and S07 do not include air injection, there is no mechanism during periods of cooling for the water to become supersaturated. Rather, the gas exchange driving force is always toward equilibrium.

[36] A second way to compare the parameterization presented here with W92 and S07 is to compare their respective estimates of the fluxes of Ar from the supersaturations predicted in the model or observed in the data. This exercise is analogous to researchers measuring concentrations of a gas in the water and then calculating the flux from the measurements. The estimated fluxes when W92 is used (Figure 7a, blue curve) or S07 is used (not shown) in this "after the fact" fashion are dramatically different than the actual fluxes. This is because in the winter, Ar is always supersaturated. W92 thus estimates a net flux out of the water. However, in reality, there is a net flux into the water because of air injection - it is this net flux into the water that is causing the supersaturation in the first place. Thus calculating the flux from saturation anoma- lies without considering air injection can lead to large errors if the gases are close to equilibrium.

[37] In some studies, $\mathrm{Ar}$ or $\mathrm{N}_{2}$ is used as an abiotic analog for $\mathrm{O}_{2}$. In order to roughly estimate the effect of not considering air injection in such studies, we conducted the following three runs of the model: (1) base case and including a simple productivity parameterization, see Stanley et al. [2006], (2) without any biological productivity but still including air injection (i.e., base case), and (3) without any biological productivity or air injection. We then compared the $\mathrm{O}_{2}, \mathrm{Ar}$, and $\mathrm{N}_{2}$ saturation anomalies from these three runs. We found that excluding air injection changes $\Delta \mathrm{O}_{2}-\Delta \mathrm{Ar}$ a negligible amount compared to the $\Delta \mathrm{O}_{2}$ anomaly from productivity. However, excluding air injection changes the $\Delta \mathrm{O}_{2}-\Delta \mathrm{N}_{2}$ to a similar magnitude as productivity changes $\Delta \mathrm{O}_{2}$. Thus it is imperative to include air injection if one is using $\mathrm{N}_{2}$ in tandem with $\mathrm{O}_{2}$.

\subsection{Uncertainty Analysis}

[38] We estimate that the uncertainty on the diffusive gas exchange parameter from this approach is $\pm 14 \%$. All error analysis described in this section reports uncertainties as $1 \sigma$
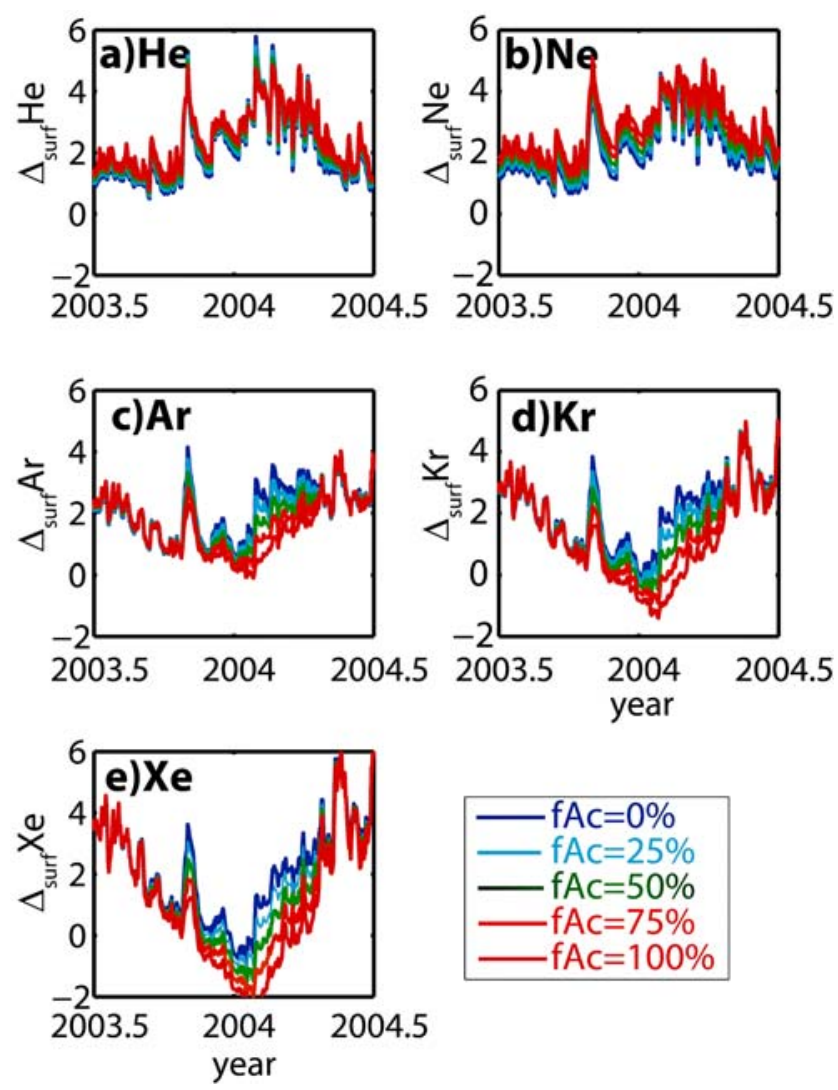

Figure 5. Sensitivity to partial versus complete trapping. Model results showing the sensitivity of the surface saturation anomaly, $\Delta_{\text {surf }}$, to the fraction of complete versus partially trapped bubbles, $f A c$. All runs had comparable amounts of total air injection but different fractions of completely versus partially trapped bubbles, ranging from $0 \%$ completely trapped $(f A c=0 \%$, blue) to $100 \%$ completely trapped $(f A c=100 \%$, red $)$. The winter Xe surface saturation anomaly is the most sensitive metric for $f A c$. 

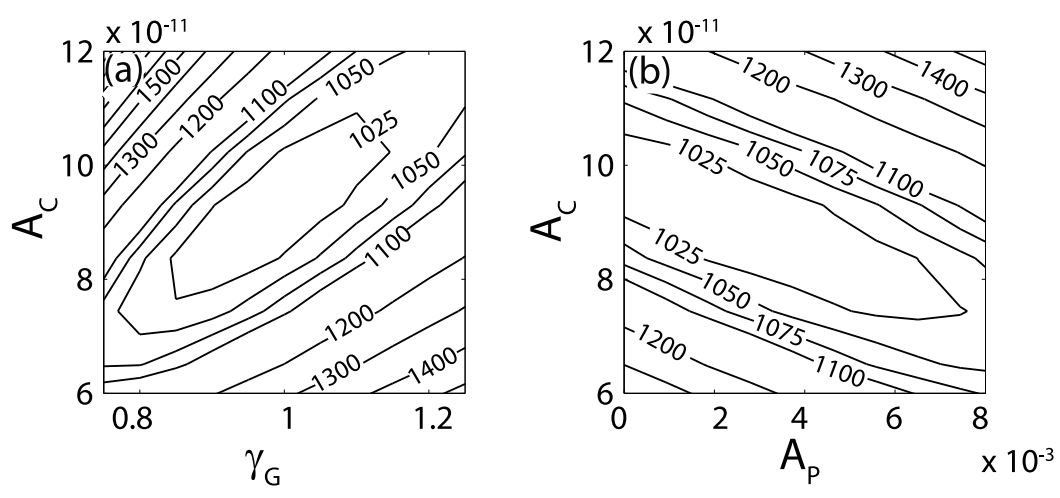

Figure 6. Cost function plotted in parameter space. The cost function is plotted as a function of (a) diffusive gas exchange parameter $\gamma_{\mathrm{G}}$ and completely trapped air injection parameter $A_{C}$ and (b) partially trapped air injection parameter $A_{P}$ and completely trapped air injection parameter $A_{C}$. In both cases, the cost function has a narrow valley, reflecting the interdependencies of the parameters. Contours are drawn every 25 units at values below 1100 and at every 100 units at values above 1100 .

values. This uncertainty includes the sum, in quadrature, of errors from three sources: (1) modeling error, (2) solubility error, and (3) lateral transport error. The modeling error component contributes $\pm 6 \%$, the solubility component contributes $\pm 8 \%$ for $\mathrm{Kr}$ solubility and $\pm 8 \%$ for Xe solubility and the lateral transport error contributes $\pm 5 \%$. The largest contribution to the error stems from the uncertainty in the solubility values of $\mathrm{Kr}$ and $\mathrm{Xe}$; once the solubilities of these gases are determined more precisely, the method and data presented in this study could be used to redetermine gas exchange parameters with even tighter constraints. The rest of this section describes in more detail these sources of error and their magnitudes.

[39] The modeling error component contains contributions from uncertainties in the physical parameters used to run the model as well as sensitivities due to different formulations of the cost function and to using data from different time periods subset from the full sampling period. In Table 1 we list the optimized gas exchange parameters that result from these different conditions. The standard deviation of the ensemble of diffusive gas exchange parameters across this full suite of sensitivity experiments is only $6 \%$. Thus we estimate the modeling error contribution to the uncertainty in the diffusive gas exchange parameter to have a $1 \sigma$ error of $6 \%$.

[40] In more detail, the first source of modeling error comes from the choice of tunable model physical parameters. As described in the methods section, we used ensemble runs to determine the best sets of certain tunable physical parameters. If we use the three sets of physical parameters that yielded the lowest cost functions, then the diffusive gas exchange parameter differs by less than $\pm 3.5 \%$. To be conservative, we also estimated the gas exchange parameterization with broader ranges of $K_{z}$ to see how uncertainty in the physical parameters contributes to uncertainty in the gas exchange. If we use a broader, but still reasonable, range of $K_{z}$ of $3 \times 10^{-5}$ to $8 \times 10^{-5} \mathrm{~m}^{2} \mathrm{~s}^{-1}$, the gas exchange parameter differs by $\pm 9 \%$ from our reference case. If we use an even broader range of $2 \times 10^{-5}$ to $1 \times 10^{-4} \mathrm{~m}^{2} \mathrm{~s}^{-1}-$ and please note this range is clearly an overestimate of the uncertainty in $K_{z}$ since the temperature and salinity data can constrain $K_{z}$ more tightly than this range suggests - the change in the diffusive gas exchange parameter is $\pm 14 \%$. Because this broader range of $\mathrm{Kz}$ is not reasonable, we do not include the values given when $\mathrm{Kz}=2 \times 10^{-5} \mathrm{~m}^{2} \mathrm{~s}^{-1}$ or $1 \times 10^{-4} \mathrm{~m}^{2} \mathrm{~s}^{-1}$ when calculating the standard deviation of the suite of runs. We also ran the model with the base case physical parameters but without temperature restoring and in that case, the diffusive gas exchange parameter only changed by $7 \%$.

[41] A second source of modeling uncertainty stems from the formulation of the cost function used to determine the gas exchange parameterizations. The cost function was based on model-data differences of noble gas surface saturation anomalies and subsurface concentrations (see Section 2.4). We examined the sensitivity of the results to shifting the balance between these two parts of the cost function as well as adding in a third component that includes the seasonal differences in the noble gas saturation anomalies. The difference in diffusive gas exchange parameter in these different formulations from the reference simulation ranged from $2 \%$ to $8 \%$.

[42] It is difficult to quantify directly the uncertainty due to the 1-D model framework and the underlying assumptions and thus such uncertainty is not directly included in our estimate of modeling error. However, one measure of such uncertainty is the difference in results if we use only one year of data instead of all three years of the time series. If we based the optimization on only the first year of data, on only the second year of data, or on only the third year of data, the results differed by $2 \%$ to $14 \%$. Overall, the narrow range in gas exchange parameter resulting from all these different formulations of the cost function and runs of the model give us confidence that the gas exchange parameters are robust to modeling error with a $1 \sigma$ uncertainty of $6 \%$, where $6 \%$ is the standard deviation of diffusive gas exchange parameter for the suite of model runs.

[43] A second source of error is that due to uncertainty in the solubility values for the heavier noble gases. The solubility functions of the noble gases in seawater were reported by Weiss [1970, 1971], Weiss and Kyser [1978], and Wood and Caputi [1966]. Recently, Hamme and Emerson [2004] redetermined the solubility of $\mathrm{Ne}$ and $\mathrm{Ar}$ and found significant differences to that of Weiss, on 

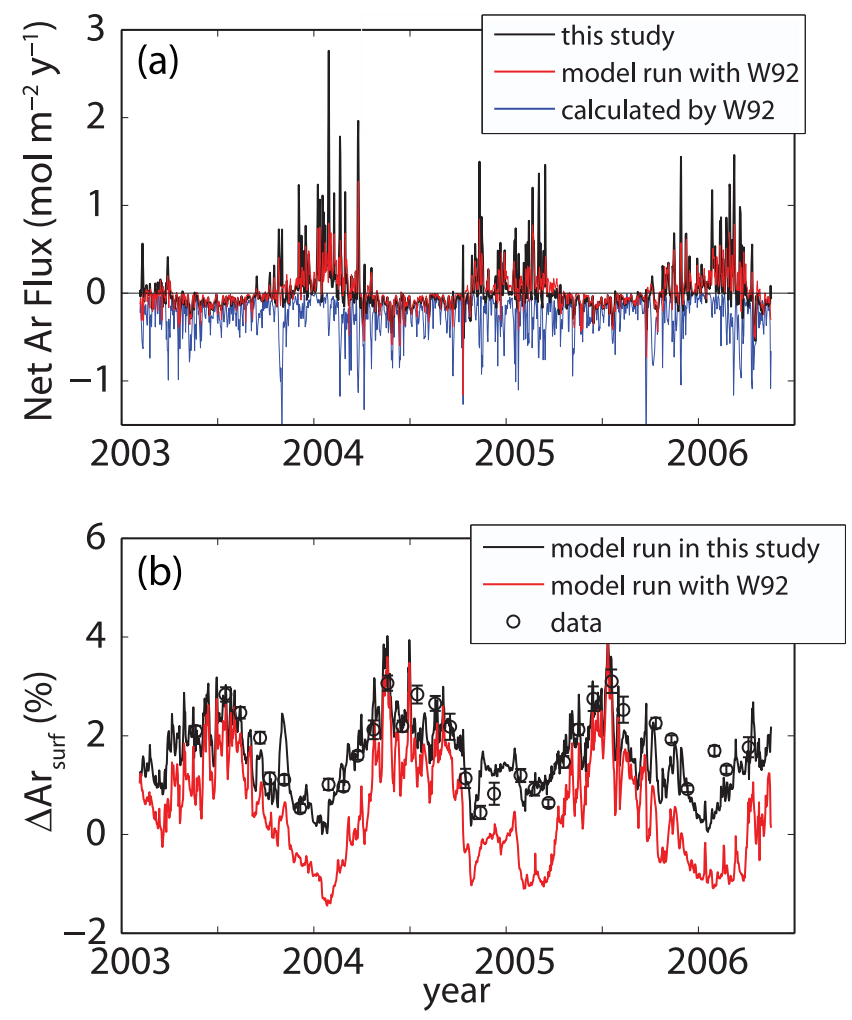

Figure 7. Comparison of net fluxes between different parameterizations. (a) The net total gas exchange flux of $\mathrm{Ar}$, which behaves in a similar fashion as $\mathrm{O}_{2}$, calculated by the model when run with the parameterization presented in this paper (black) is compared with the net flux calculated by the model run with the Wanninkhof [1992, hereinafter W92] parameterization (red). In blue, we show the net flux calculated from combining surface saturation anomalies of the noble gases directly with W92 (i.e., no model). These fluxes are all different, highlighting the importance of explicitly including an air injection component. (b) Saturation anomalies of $\mathrm{Ar}$ as measured (o), as modeled when using the parameterization presented in this paper (black) and as modeled when using W92 (red). Note that because W92 does not explicitly include air injection processes, it fails to achieve the observed winter supersaturation of Ar.

the order of $1 \%$. It is likely that the $\mathrm{Kr}$ and $\mathrm{Xe}$ solubilities may be wrong as well. Thus, we estimate the error due to uncertainty in the solubility functions of the heavier noble gases by performing the optimization with a systematic shift in solubility functions of $\pm 1 \%$ for $\mathrm{Kr}$ and $\pm 1.5 \%$ for $\mathrm{Xe}$. This source of error contributes $\pm 8 \%$ to the diffusive gas exchange parameter from $\mathrm{Kr}$ and $\pm 8 \%$ from $\mathrm{Xe}$.

[44] Third, we assess the error due to potential lateral advection of dissolved gases in the upper water column by including a lateral gas advection compensation term calculated using the estimated net heat convergence at the BATS site and the temperature dependence of the solubility of the gases. We multiply estimates of the heat imbalance by $\mathrm{d} C_{i, e q} / \mathrm{d} T$, the derivative of the solubility of the gas with respect to temperature, for each of the gases and then add this amount of gas in to the surface box at each time step. We then compare the parameters estimated from using the inverse approach with these runs to the reference case parameters to estimate the uncertainty due to the lateral flux. The gases may not reach equilibrium during lateral transport so this approach estimates the maximum possible error. Two different estimates of heat imbalance [Grist and Josey, 2003; Yu and Weller, 2007] yield a range of gas exchange parameter of 0.89 to 0.96 . Thus we estimate the uncertainty in this term as $\pm 5 \%$.

[45] For air injection, we compute the uncertainty in a similar way as for diffusive gas exchange. The air injection modeling error is $\pm 13 \%$, solubility uncertainty error is $\pm 17 \%$ for $\mathrm{Kr}$ and $\pm 18 \%$ for $\mathrm{Xe}$, and lateral advection error is $\pm 6 \%$, where all errors are reported as $1 \sigma$ values. The total error for air injection is the sum, in quadrature, of these contributions, and is equal to $\pm 29 \%$.

[46] Other sources of error include uncertainties in the products that were used to force the model - notably the QuikSCAT winds and the NCEP reanalysis heat fluxes. We did not explicitly include the error from these sources. We have computed the uncertainty in the gas exchange parameters with QuikSCAT winds (not some idealized true winds) and thus the errors in QuikSCAT (estimated to be $0.75 \mathrm{~m} \mathrm{~s}^{-1}$ in the along-wind direction and $1.5 \mathrm{~m} \mathrm{~s}^{-1}$ in the crosswind direction [Chelton and Freilich, 2005]) are embedded in the parameter estimates. Errors and biases of the QuikSCAT winds would only be important if a different wind product were used. In that case, the gas exchange parameters should be adjusted for the wind biases between products. However, given that QuikSCAT wind data are readily available and are arguably the most accurate wind product, this restriction to QuikSCAT winds does not limit the utility of the parameterization.

[47] We account for errors in the NCEP reanalysis heat fluxes through the use of the tunable physical parameters. From the perspective of the model, it is not necessary to distinguish between a systematic error in the NCEP heat flux and a genuine nonzero residual in the air-sea heat flux, as long as this bias is temporally uniform and does not have a strong seasonal variation. Our objective is simply to assert a long-term (multiyear) balance using an artificially imposed horizontal heat flux divergence in order to achieve long-term stability in the model. We adequately simulate the observed seasonal changes in the upper ocean thermal structure, and we feel that given the limitations of 1-D upper ocean models [Doney, 1996] this is sufficient in order to characterize the forcing for the gas concentrations.

\subsection{Contributions of the Different Gases to Constraining the Parameters}

[48] In order to assess which gases are controlling the values of the parameters, we performed a "knockout" study where we systematically deweighted the contribution of the model-observation terms for each gas in the cost function to examine how the parameters changed if we excluded a particular gas. The diffusive gas exchange parameter, $\gamma_{\mathrm{G}}$, changed by at most $9 \%$ if any one gas was excluded from the cost function (Table 2). The total air injection flux changes by up to $25 \%$ if one of the gases is excluded. The largest total air injection flux is predicted when $\mathrm{Ne}$ is excluded. Helium and $\mathrm{Ne}$ are playing off each other to some extent with the He data pointing to a larger air injection flux and the Ne data pointing to a smaller air injection flux. This 
Table 2. Parameter Values Calculated Using the Nonlinear Optimization Scheme When One Gas Was Excluded From the Cost Function ${ }^{\mathrm{a}}$

\begin{tabular}{cccccc}
\hline Gas Excluded & $\gamma_{\mathrm{G}}$ & $\mathrm{Ac}\left(\times 10^{3}\right)$ & $\mathrm{Ap}\left(\times 10^{-5}\right)$ & $\begin{array}{c}\text { Total Air Injection Flux } \\
\left(\times 10^{7} \mathrm{~mol} \mathrm{~m}^{-2} \mathrm{~s}^{-1}\right)\end{array}$ & $\begin{array}{c}\text { Fraction Completely } \\
\text { Trapped Bubbles }(\%)\end{array}$ \\
\hline None & 0.97 & 9.09 & 2.29 & 3.99 & 97 \\
$\mathrm{He}$ & 0.98 & 8.44 & 3.75 & 3.89 & 95 \\
$\mathrm{Ne}$ & 1.01 & 11.14 & 0 & 4.88 & 100 \\
$\mathrm{Ar}$ & 1.02 & 9.36 & 0.19 & 4.11 & 90 \\
$\mathrm{Kr}$ & 0.94 & 8.62 & 2.89 & 3.92 & 96 \\
$\mathrm{Xe}$ & 0.93 & 8.75 & 2.30 & 3.95 & 97 \\
\hline
\end{tabular}

${ }^{\mathrm{a}}$ The base case is included in the first line for reference purposes.

may be related to uncertainties in the solubility of He. The fraction of complete versus partial air injection changes by at most $5 \%$ if one of the gases is excluded. The small differences in parameters when any one gas is excluded gives us confidence in the robustness of our results since it shows they do not depend on only one gas in particular. This knockout study is based on current analytical precision and the limitations on the solubility functions. Improvements in both of these areas may change the texture of the gas dependency.

\section{Conclusions}

[49] In summary, because the five noble gases have a wide range in physicochemical characteristics and are biologically and chemically inert, their simultaneous time series measurement provides a valuable tool for diagnosing air-sea exchange on seasonal timescales. The uncertainty in the diffusive gas exchange parameterization presented here is approximately half the size of other commonly used parameterizations [Wanninkhof, 1992; Wanninkhof and McGillis, 1999; Nightingale et al., 2000; Ho et al., 2006; Sweeney et al., 2007]. This reduced uncertainty is a result of (1) our using five noble gases allowing us to separate and quantify diffusive gas exchange and air injection separately and (2) our method being based on seasonal measurements instead of the much shorter or longer time scales of other parameterizations. Additionally, because we base our parameterization on scatterometer winds, we may be partially accounting for the effects of surfactants. The parameterization presented here explicitly includes air injection, which we show is significant.

[50] Note that these estimates of gas exchange parameters are determined using QuikSCAT winds. If a different wind product is used (NCEP reanalysis winds for example) then adjustment would need to be made. These estimates are valid over the range of wind speeds observed at Bermuda $\left(0-13 \mathrm{~m} \mathrm{~s}^{-1}\right)$ and for open ocean, oligotrophic waters low in surfactants [Frew et al., 2004] Such waters represent a large proportion of the world's oceans (more than $75 \%$ by area), making this work applicable in many settings. The parameterizations determined through the noble gases can now be applied to calculate more accurate and precise fluxes of $\mathrm{CO}_{2}, \mathrm{O}_{2}$ and other gases of climatic importance.

[51] Future work should include using this time series of noble gas data in combination with satellite altimetry and backscatter measurements in order to calibrate air-sea gas exchange flux parameterized as a function of surface roughness as well as wind speed [Woolf, 2005; Fangohr and Woolf, 2007; Frew et al., 2007; Glover et al., 2007]. Some of the variability in existing parameterizations of air- sea gas exchange, including the one proposed here, may be because the diffusive part of the gas transfer rate does not directly depend on wind speed but rather on the frequency spectrum of the divergence field at the surface and thus is a function of surface roughness, surfactant films, sea state, etc. The data set collected here, in combination with satellite records of surface altimetry and mean square slope, could offer the valuable opportunity for constraining a parameterization of air-sea gas exchange based on surface roughness. Additionally, the noble gas data set could be useful for constraining more complicated models of bubble dynamics than the relatively simple model used currently.

[52] Acknowledgments. We thank Michael Lomas, Rod Johnson, all other scientists associated with the BATS program, and the captain and crew of the R/V Weatherbird II for assistance in collecting samples. We are grateful to funding from the National Science Foundation Chemical Oceanography program (OCE-0221247 and OCE-0623034).

\section{References}

Asher, W. E., and R. Wanninkhof (1998), The effect of bubble-mediated gas transfer on purposeful dual-gaseous tracer experiments, J. Geophys. Res., 103(C5), 10,555-10,560, doi:10.1029/98JC00245.

Bender, M. L., D. T. Ho, M. B. Hendricks, R. Mika, M. O. Battle, P. P. Tans, T. J. Conway, B. Sturtevant, and N. Cassar (2005), Atmospheric $\mathrm{O}_{2} / \mathrm{N}_{2}$ changes, 1993-2002: Implications for the partitioning of fossil fuel $\mathrm{CO}_{2}$ sequestration, Global Biogeochem. Cycles, 19, GB4017, doi:10.1029/2004GB002410.

Blomquist, B. W., C. W. Fairall, B. J. Huebert, D. J. Kieber, and G. R Westby (2006), DMS sea-air transfer velocity: Direct measurements by eddy covariance and parameterization based on the NOAA/COARE gas transfer model, Geophys. Res. Lett., 33, L07601, doi:10.1029/ 2006GL025735.

Chelton, D. B., and M. H. Freilich (2005), Scatterometer-based assessment of $10-\mathrm{m}$ wind analyses from the operational ECMWF and NCEP numerical weather prediction models, Mon. Weather Rev., 133(2), 409-429, doi:10.1175/MWR-2861.1.

Craig, H., and T. Hayward (1987), Oxygen supersaturation in the ocean: Biological versus physical contributions, Science, 235, 199-202, doi:10.1126/science.235.4785.199.

Dickey, T., et al. (1998), Initial results from the Bermuda Testbed Mooring program, Deep Sea Res. Part I, 45(4-5), 771-794, doi:10.1016/S09670637(97)00096-4.

Doney, S. C. (1996), A synoptic atmospheric surface forcing data set and physical upper ocean model for the U.S. JGOFS Bermuda Atlantic TimeSeries Study site, J. Geophys. Res., 101(C11), 25,615-25,634, doi:10.1029/96JC01424.

Doney, S. C., K. Lindsay, I. Fung, and J. John (2006), Natural variability in a stable 1000 year coupled climate-carbon cycle simulation, J. Clim., 19(13), 3033-3054, doi:10.1175/JCLI3783.1.

Doney, S. C., B. Tilbrook, S. Roy, N. Metzl, C. Le Quere, M. Hood, R. A. Feely, and D. Bakker (2009), Surface ocean $\mathrm{CO}_{2}$ variability and vulnerability, Deep Sea Res. Part II, 56(8-10), 504-511.

Emerson, S. (1987), Seasonal oxygen cycles and biological new production in surface waters of the subarctic Pacific Ocean, J. Geophys. Res., 92(C6), 6535-6544, doi:10.1029/JC092iC06p06535.

Fangohr, S., and D. K. Woolf (2007), Application of new parameterizations of gas transfer velocity and their impact on regional and global marine $\mathrm{CO}_{2}$ budgets, J. Mar. Syst., 66(1-4), 195-203, doi:10.1016/ j.jmarsys.2006.01.012. 
Frew, N. M., et al. (2004), Air-sea gas transfer: Its dependence on wind stress, small-scale roughness, and surface films, J. Geophys. Res., 109, C08S17, doi:10.1029/2003JC002131.

Frew, N. M., D. M. Glover, E. J. Bock, and S. J. McCue (2007), A new approach to estimation of global air-sea gas transfer velocity fields using dual-frequency altimeter backscatter, J. Geophys. Res., 112, C11003, doi:10.1029/2006JC003819.

Fuchs, G., W. Roether, and P. Schlosser (1987), Excess ${ }^{3} \mathrm{He}$ in the ocean surface layer, J. Geophys. Res., 92, 6559-6568, doi:10.1029/ JC092iC06p06559.

Glover, D. M., N. M. Frew, and S. J. McCue (2007), Air-sea gas transfer velocity estimates from the Jason-1 and TOPEX altimeters: Prospects for a long-term global time series, J. Mar. Syst., 66(1-4), 173-181, doi:10.1016/j.jmarsys.2006.03.020.

Graham, A., D. K. Woolf, and A. J. Hall (2004), Aeration due to breaking waves. Part I: Bubble populations, J. Phys. Oceanogr., 34(5), 989-1007, doi:10.1175/1520-0485(2004)034<0989:ADTBWP>2.0.CO;2.

Grist, J. P., and S. A. Josey (2003), Inverse analysis adjustment of the SOC air-sea flux climatology using ocean heat transport constraints, J. Clim., 16(20), 3274-3295, doi:10.1175/1520-0442(2003)016< 3274:IAAOTS $>2$.0.CO;2.

Hamme, R. C., and S. R. Emerson (2004), The solubility of neon, nitrogen and argon in distilled water and seawater, Deep Sea Res. Part I, 51(11), $1517-1528$

Hamme, R. C., and S. R. Emerson (2006), Constraining bubble dynamics and mixing with dissolved gases: Implications for productivity measurements by oxygen mass balance, J. Mar. Res., 64(1), 73-95, doi:10.1357/ 002224006776412322.

Hare, J. E., C. W. Fairall, W. R. McGillis, J. B. Edson, B. Ward, and R. Wanninkhof (2004), Evaluation of the National Oceanic and Atmospheric Administration/Coupled-Ocean Atmospheric Response Experiment (NOAA/COARE) air-sea gas transfer parameterization using GasEx data, J. Geophys. Res., 109, C08S11, doi:10.1029/2003JC001831.

Hendricks, M. B., M. L. Bender, and B. A. Barnett (2004), Net and gross $\mathrm{O}_{2}$ production in the Southern Ocean from measurements of biological $\mathrm{O}_{2}$ saturation and its triple isotope composition, Deep Sea Res. Part I, $51(11), 1541-1561$.

Ho, D. T., C. S. Law, M. J. Smith, P. Schlosser, M. Harvey, and P. Hill (2006), Measurements of air-sea gas exchange at high wind speeds in the Southern Ocean: Implications for global parameterizations, Geophys. Res. Lett., 33, L16611, doi:10.1029/2006GL026817.

Jenkins, W. J. (1988a), Nitrate flux into the euphotic zone near Bermuda, Nature, 331(6156), 521-523, doi:10.1038/331521a0.

Jenkins, W. J. (1988b), The use of anthropogenic tritium and He-3 to study sub-tropical gyre ventilation and circulation, Philos. Trans. R. Soc. London Ser. $A, 325(1583), 43-61$

Jenkins, W. J., and S. C. Doney (2003), The subtropical nutrient spiral, Global Biogeochem. Cycles, 17(4), 1110, doi:10.1029/2003GB002085.

Jenkins, W. J., and J. C. Goldman (1985), Seasonal oxygen cycling and primary production in the Sargasso Sea, J. Mar. Res., 43(2), 465-491, doi:10.1357/002224085788438702.

Jin, X., R. G. Najjar, F. Louanchi, and S. C. Doney (2007), A modeling study of the seasonal oxygen budget of the global ocean, J. Geophys. Res., 112, C05017, doi:10.1029/2006JC003731.

Kalnay, E., et al. (1996), The NCEP/NCAR 40-year reanalysis project, Bull. Am. Meteorol. Soc., 77(3), 437-471, doi:10.1175/1520-0477(1996)077< 0437:TNYRP $>2.0 . \mathrm{CO} ; 2$.

Keeling, R. F. (1993), On the role of large bubbles in air-sea gas-exchange and supersaturation in the ocean, J. Mar. Res., 51(2), 237-271, doi:10.1357/0022240933223800.

Keeling, R. F., R. G. Najjar, M. L. Bender, and P. P. Tans (1993), What atmospheric oxygen measurements tell us about the global carbon cycle, Global Biogeochem. Cycles, 7(1), 37-67, doi:10.1029/92GB02733.

Large, W. G., J. C. McWilliams, and S. C. Doney (1994), Oceanic vertical mixing-A review and a model with a nonlocal boundary-layer parameterization, Rev. Geophys., 32(4), 363-403, doi:10.1029/94RG01872.

Ledwell, J. R., A. J. Watson, and C. S. Law (1993), Evidence for slow mixing across the pycnocline from an open-ocean tracer-release experiment, Nature, 364(6439), 701-703, doi:10.1038/364701a0.

Ledwell, J. R., A. J. Watson, and C. S. Law (1998), Mixing of a tracer in the pycnocline, J. Geophys. Res., 103(C10), 21,499-21,529, doi:10.1029/ 98JC01738.

Liss, P. S., and L. Merlivat (1986), Air-sea gas exchange rates: Introduction and synthesis, in The Role of Air-Sea Gas Exchange in Geochemical Cycling, edited by P. Buart-Menard, pp. 113-127, D. Reidel, Norwell, Mass.

Lott, D. E. (2001), Improvements in noble gas separation methodology: A nude cryogenic trap, Geochem. Geophys. Geosyst., 2(12), 1068 , doi:10.1029/2001GC000202.

Lott, D. E., and W. J. Jenkins (1998), Advances in analysis and shipboard processing of tritium and helium samples, Int. WOCE Newsl., 30, 27-30.
McKinley, G. A., M. J. Follows, J. Marshall, and S. M. Fan (2003), Interannual variability of air-sea $\mathrm{O}_{2}$ fluxes and the determination of $\mathrm{CO}_{2}$ sinks using atmospheric $\mathrm{O}_{2} / \mathrm{N}_{2}$, Geophys. Res. Lett., 30(3), 1101, doi:10.1029/ 2002GL016044.

McNeil, C., and E. D'Asaro (2007), Parameterization of air-sea gas fluxes at extreme wind speeds, J. Mar. Syst., 66(1-4), 110-121, doi:10.1016/ j.jmarsys.2006.05.013.

Monahan, E. C., and T. Torgersen (1990), Enhancement of air-sea gas exchange by oceanic whitecapping, in Air-Water Mass Transfer: Selected Papers from the Second International Symposium on Gas Transfer at Water Surfaces, edited by S. C. Wilhelms and J. S. Gulliver, pp. 608617, Am. Soc. of Civ. Eng., New York.

Najjar, R. G., and R. F. Keeling (2000), Mean annual cycle of the air-sea oxygen flux: A global view, Global Biogeochem. Cycles, 14(2), 573584, doi:10.1029/1999GB900086.

Nightingale, P. D., G. Malin, C. S. Law, A. J. Watson, P. S. Liss, M. I. Liddicoat, J. Boutin, and R. C. Upstill-Goddard (2000), In situ evaluation of air-sea gas exchange parameterizations using novel conservative and volatile tracers, Global Biogeochem. Cycles, 14(1), 373-387, doi:10.1029/1999GB900091.

Polzin, K. L., N. S. Oakey, J. M. Toole, and R. W. Schmitt (1996), Fine structure and microstructure characteristics across the northwest Atlantic Subtropical Front, J. Geophys. Res., 101(C6), 14,111-14,121, doi:10.1029/96JC01020.

Price, J. F., R. A. Weller, and R. Pinkel (1986), Diurnal cycling: Observations and models of the upper ocean response to diurnal heating, cooling, and wind mixing, J. Geophys. Res., 91(C7), 8411-8427, doi:10.1029/ JC091iC07p08411.

Reuer, M. K., B. A. Barnett, M. L. Bender, P. G. Falkowski, and M. B. Hendricks (2007), New estimates of Southern Ocean biological production rates from $\mathrm{O}_{2} / \mathrm{Ar}$ ratios and the triple isotope composition of $\mathrm{O}_{2}$, Deep Sea Res. Part I, 54(6), 951-974, doi:10.1016/j.dsr.2007.02.007.

Spitzer, W. S., and W. J. Jenkins (1989), Rates of vertical mixing, gasexchange and new production: Estimates from seasonal gas cycles in the upper ocean near Bermuda, J. Mar. Res., 47(1), 169-196, doi:10.1357/ 002224089785076370 .

Stanley, R. H. R. (2007), Air-sea gas exchange and upper ocean biological production, Ph.D. thesis, Mass. Inst. of Technol. and Woods Hole Oceanogr. Inst. Joint Prog., Woods Hole, Mass.

Stanley, R. H. R., W. J. Jenkins, and S. C. Doney (2006), Quantifying seasonal air-sea gas exchange processes using noble gas time-series: A design experiment, J. Mar. Res., 64(2), 267-295, doi:10.1357/ 002224006777606452 .

Stanley, R. H. R., B. Baschek, D. E. Lott III, and W. J. Jenkins (2009), A new automated method for measuring noble gases and their isotopic ratios in water samples, Geochem. Geophys. Geosyst., 10, Q05008, doi:10.1029/2009GC002429.

Sweeney, C., E. Gloor, A. R. Jacobson, R. M. Key, G. McKinley, J. L. Sarmiento, and R. Wanninkhof (2007), Constraining global air-sea gas exchange for $\mathrm{CO}_{2}$ with recent bomb ${ }^{14} \mathrm{C}$ measurements, Global Biogeochem. Cycles, 21, GB2015, doi:10.1029/2006GB002784.

Takahashi, T., R. A. Feely, R. F. Weiss, R. H. Wanninkhof, D. W. Chipman, S. C. Sutherland, and T. T. Takahashi (1997), Global air-sea flux of $\mathrm{CO}_{2}$ An estimate based on measurements of sea-air $\mathrm{pCO}_{2}$ difference, Proc. Natl. Acad. Sci. U. S. A., 94(16), 8292-8299, doi:10.1073/pnas. 94.16.8292.

Takahashi, T., et al. (2002), Global sea-air $\mathrm{CO}_{2}$ flux based on climatological surface ocean $\mathrm{pCO}_{2}$, and seasonal biological and temperature effects, Deep Sea Res. Part II, 49(9-10), 1601-1622, doi:10.1016/S09670645(02)00003-6.

Wanninkhof, R. (1992), Relationship between wind speed and gas exchange over the ocean, J. Geophys. Res., 97(C5), 7373-7382, doi:10.1029/92JC00188.

Wanninkhof, R., and W. R. McGillis (1999), A cubic relationship between air-sea $\mathrm{CO}_{2}$ exchange and wind speed, Geophys. Res. Lett., 26(13), 1889-1892, doi:10.1029/1999GL900363.

Weiss, R. F. (1970), The solubility of nitrogen, oxygen and argon in water and seawater, Deep Sea Res., 17, 721-735.

Weiss, R. F. (1971), Solubility of helium and neon in water and seawater, J. Chem. Eng. Data, 16, 235-241, doi:10.1021/je60049a019.

Weiss, R. F., and T. K. Kyser (1978), Solubility of krypton in water and seawater, J. Chem. Eng. Data, 23(1), 69-72, doi:10.1021/je60076a014.

Wood, D., and R. Caputi (1966), Solubilities of $\mathrm{Kr}$ and Xe in Fresh and Sea Water, report, 14 pp., U.S. Nav. Radiol. Def. Lab., San Francisco, Calif Woolf, D. K. (1993), Bubbles and the air-sea transfer velocity of gases, Atmos. Ocean, 31(4), 517-540.

Woolf, D. K. (1997), Bubbles and their role in gas exchange, in The Sea Surface and Global Change, edited by R. Duce and P. S. Liss, pp. 173205, Cambridge Univ. Press, New York. 
Woolf, D. K. (2005), Parametrization of gas transfer velocities and seastate-dependent wave breaking, Tellus Ser. B, 57(2), 87-94, doi:10.1111/j.1600-0889.2005.00139.x.

Woolf, D. K., and S. A. Thorpe (1991), Bubbles and the air-sea exchange of gases in near-saturation conditions, J. Mar. Res., 49(3), 435-466, doi:10.1357/002224091784995765.

Woolf, D. K, et al. (2007), Modelling of bubble-mediated gas transfer: Fundamental principles and a laboratory test, J. Mar. Syst., 66(1-4), 71-91, doi:10.1016/j.jmarsys.2006.02.011
Yu, L., and R. A. Weller (2007), Objectively analyzed air-sea heat fluxes (OAFlux) for the global oceans, Bull. Am. Meteorol. Soc., 88, 527-539, doi:10.1175/BAMS-88-4-527.

Zhang, W. Q., W. Perrie, and S. Vagle (2006), Impacts of winter storms on air-sea gas exchange, Geophys. Res. Lett., 33, L14803, doi:10.1029/ 2005GL025257.

S. C. Doney, W. J. Jenkins, D. E. Lott III, and R. H. R. Stanley, Department of Marine Chemistry and Geochemistry, Woods Hole Oceanographic Institution, 266 Woods Hole Rd., Woods Hole, MA 02453, USA. (sdoney@whoi.edu; wjenkins@whoi.edu; dlott@whoi.edu; rstanley@ whoi.edu) 